4.3 Emigration to most common destinations of next residence for 2010, shown for 2006 2010

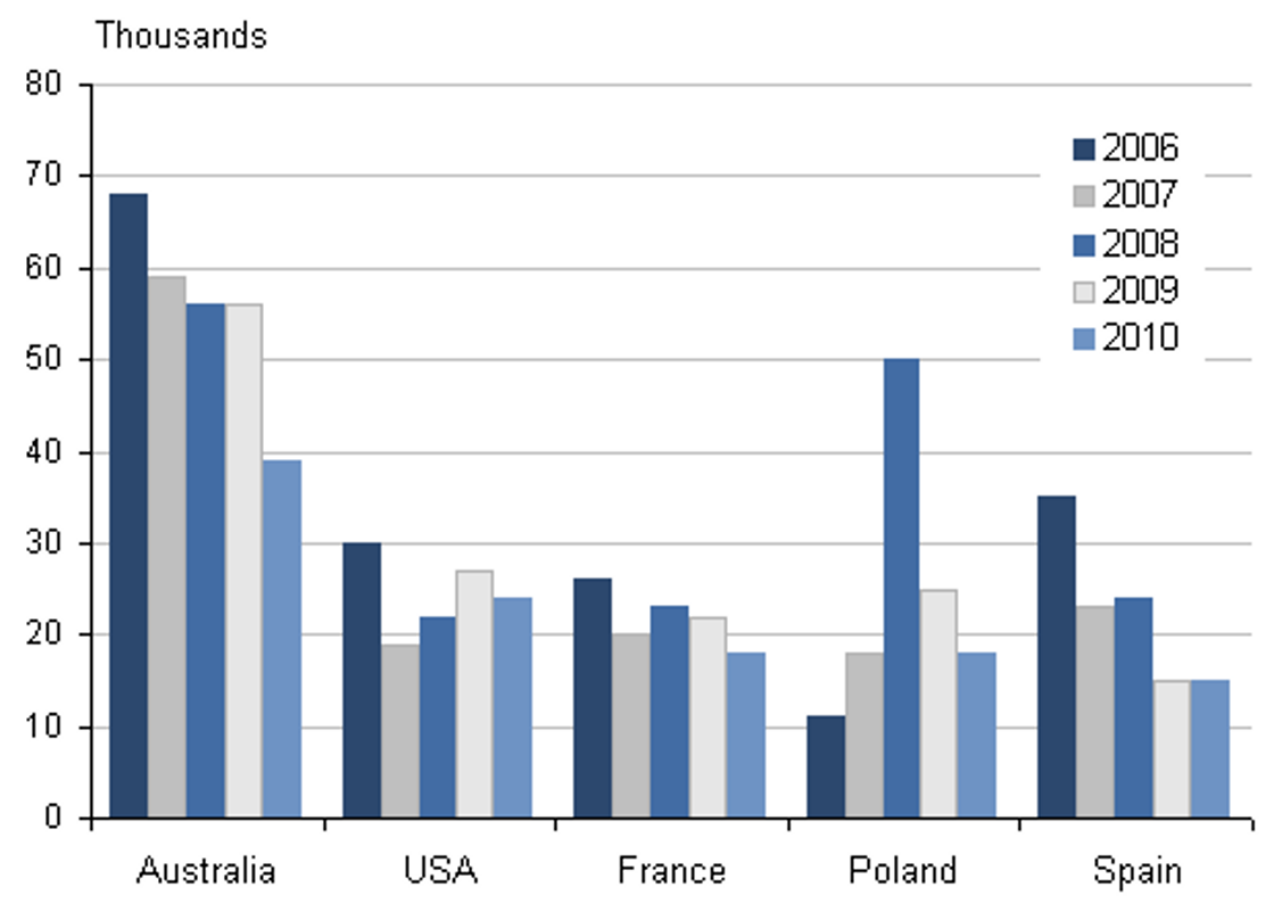

Source: Office for National Statistics

Download chart

XLS XLS format

$(21 \mathrm{~Kb})$

\title{
5. Summary of Other Releases
}

Other migration and population products published on 24 November 2011 include:

- A short story on emigration

- The online internal migration dataset contains a full matrix of migration flows between each UK country/region, and is available for every quarter since the year to June 2002. Data for earlier years are available on request

Links to these products are included in the list of products

\section{Changes to the Migration Statistics Quarterly Report}

In August 2011 the MSQR was structured differently from previous editions and followed the questions 